Short Communication

\title{
Expressional changes of RyR1 and RyR2 in PC12 cells after induction of apoptosis
}

\author{
Dana Jurkovicova, Lubomira Lencesova and Olga Krizanova \\ Institute of Molecular Physiology and Genetics, Centre of Excellence for Cardiovascular Research, Slovak Academy of \\ Sciences, Bratislava, Slovakia
}

\begin{abstract}
Ca}^{2+}$ released from endoplasmic reticulum through ryanodine receptors (RyRs) and inositol 1,4,5-trisphosphate receptors (IP3Rs) can trigger apoptotic or necrotic pathways in cooperation with proapoptotic and/or prosurvival proteins, as those of Bcl-2 family. In such regulatory pathways expressional modulation of these $\mathrm{Ca}^{2+}$ transporters could also be expected. Therefore, our aim was to determine the expressional changes of RyR1 and RyR2 after experimental induction of apoptosis in PC1 2 cells. Our results showed significant decrease of RyR1 and RyR2 expressions, while caspase- 3 and Bax expression significantly increased. We conclude that induction of apoptosis in PC12 cells could result in RyR expression down regulation.
\end{abstract}

Key words: Ryanodine receptors - Gene expression - Apoptosis - PC12 cells

\begin{abstract}
Abbreviations: ER, endoplasmic reticulum; IP3R, inositol 1,4,5-trisphosphate receptor; RyR, ryanodine receptor; SERCA, sarco(endo)plasmic reticulum $\mathrm{Ca}^{2+}$ ATP-ase; ROS, reactive oxygen species; si-RyR2, small interfering RNA targeting RyR2; AIK, Apoptosis Inducer Kit.
\end{abstract}

Apoptosis as well as inappropriate activation of cell death pathways are involved in pathogenesis of many disorders such as cardiomyocyte injury, diabetes, cerebral ischemia, various neuronal disorders and others. There are multiple programmed cell death pathways and in many of those, endoplasmic reticulum (ER) is importantly involved. ER is the main intracellular calcium store that releases $\mathrm{Ca}^{2+}$ to the matrix via inositol 1,4,5-trisphosphate receptors (IP3Rs) and ryanodine receptors (RyRs) and re-uptakes $\mathrm{Ca}^{2+}$ by action of sarco(endo)plasmic reticulum $\mathrm{Ca}^{2+}$ ATP-ase (SERCA). RyRs and IP3Rs play a central role in cell survival (Ruiz et al. 2009), but it has been shown that these receptors can also be crucial in apoptotic and necrotic cell death (Hajnóczky et al. 2000).

RyRs are distributed evenly throughout the cell (Straub et al. 2000) and augment $\mathrm{Ca}^{2+}$-signal after small increase of $\mathrm{Ca}^{2+}$ released from IP3Rs concentrated mainly in the apical region of the cell (Nathanson et al. 1994), phenomenon

Correspondence to: Dana Jurkovicova, Institute of Molecular Physiology and Genetics, Slovak Academy of Sciences, Vlarska 5, 83334 Bratislava, Slovakia

E-mail: dana.jurkovicova@savba.sk known as calcium-induced calcium release (CICR). Inhibition of RyRs and $\mathrm{Ca}^{2+}$ release from ER during excitotoxic insult results in attenuation of cytosolic $\mathrm{Ca}^{2+}$ increase, mitochondrial membrane depolarization, ROS generation and activation of caspase-3 (Ruiz et al. 2009). Guo et al. (2010) showed that si-RyR2 prevented cell injury associated with attenuating cytosolic $\mathrm{Ca}^{2+}$ and ROS production in cardiomyocytes. Intracellular $\mathrm{Ca}^{2+}$ overload as well as ROS generation appears to be crucial for induction of cell death during reperfusion and reoxygenation.

There are two main pathways through which ER can induce apoptosis. Mitochondrial-dependent pathway consisting on a $\mathrm{Ca}^{2+}$ overload from ER to mitochondria is the first. These organelles are functionally coupled by microdomains that involve RyRs and IP3Rs (Rizzuto et al. 2009) and $\mathrm{Ca}^{2+}$ signaling between them can induce apoptosis crosstalk followed by cytochrome $c$ release (Ferreiro et al. 2008). The other pathway is activated by impairment of ER functioning. When unfolded proteins accumulate or ER calcium stores are depleted, highly conserved stress response is initiated and ER attempts to restore its capacity and shuts down translation and overexpress ER function-related proteins (Ruiz et al. 2009). 
Programmed cell death is regulated by number of „players" - prosurvival and proapoptotic. Major regulators of mitochondrial-mediated cell death pathways belong to the proteins of $\mathrm{Bcl}-2$ family. This family includes proapoptotic proteins such as Bax, Bak and tBid. Bax and Bak form channels in the outer mitochondrial membrane allowing the release of proapoptogenic signals such as cytochrome $c$ (Gerasimenko et al. 2010). On the other hand, prosurvival $\mathrm{Bcl}-\mathrm{xL}$ and Bcl-2 bind to and sequester the proapoptotic proteins resulting in inhibition of apoptosis. It is known that Bcl-2 family proteins can also physically and functionally regulate release of $\mathrm{Ca}^{2+}$ from intracellular stores (Rong and Distelhorst 2008).

The aim of our study was to determine expressional changes of both RyR1 and RyR2 after experimental induction of apoptosis. In our experiments we used PC12 cells, a cell line derived from a rat pheochromocytoma cells. These cells are routinely used in our laboratory and express both RyR1 and RyR2 receptors. Cells were cultured in DMEM (Dulbeco Modified Eagle's Medium) with 10\% FCS (fetal calf serum), in 6-well tissue culture plates at density of $1.0 \times 10^{6}$ in $3 \mathrm{ml}$ of media and incubated at $37^{\circ} \mathrm{C}$ in a humidified atmosphere of $5 \% \mathrm{CO}_{2}$ air for 24 hours before apoptosis induction. Apoptosis was induced by Apoptosis Inducer Kit (Calbiochem, Merck Biosciences, Germany) diluted $1: 1000$ according to manufacturer's protocol during 3 and 6 hours. The kit contains 5 chemical reagents (actinomycin D, camptothecin, etoposide, cycloheximide and dexamethasone) inducing apoptosis through different mechanisms. After induction of apoptosis, cells were used for RNA isolation and RT-PCR analysis of gene expression as described by Jurkovicova et al. (2007). Exprimed proteins were analyzed by Western blot analysis (Hudecova et al. 2010) with subsequent immunodetection with specific antibodies against RyR1 and RyR2 (Chemicon, Millipore, USA). Results are presented as means \pm S.E.M. Statistical analysis was done by Student's $t$-test. Statistical significance $p<0.05$ was considered significant.

Amplification of apoptotic genes caspase- 3 and Bax by RT-PCR verified apoptosis induction in PC12 cells. After 3 hours of apoptosis induction, caspase-3 mRNA expression increased significantly compared to control from $100.0 \pm$ 18.2 to $164.8 \pm 9.1 \%(p<0.05)$ and after 6 hours of induction from $100.0 \pm 5.0$ to $153.0 \pm 11.8 \%(p<0.01)$ (Fig. 1A). Controls were adjusted to $100 \%$. Similarly Bax gene mRNA expression raised significantly after 3 hours from $100.0 \pm 3.3$ to $293.0 \pm 45.0 \%(p<0.01)$ and after 6 hours from $100.0 \pm$ 7.2 to $183.0 \pm 15.4 \%(p<0.01)$ (Fig. 1B). These results point to entering of PC12 cells into apoptosis. Our experiments were focused on changes of mRNA and protein expression of RyR1 and RyR2. RyR1 mRNA expression significantly decreased after 3 hours of apoptosis induction from $100.0 \pm 1.3$ to $71.0 \pm 7.4 \%(p<0.05)$ and after 6 hours of treatment from $100.0 \pm 11.8$ to $59.0 \pm 7.1 \%(p<0.05)$ (Fig. $2 \mathrm{~A})$. We detected
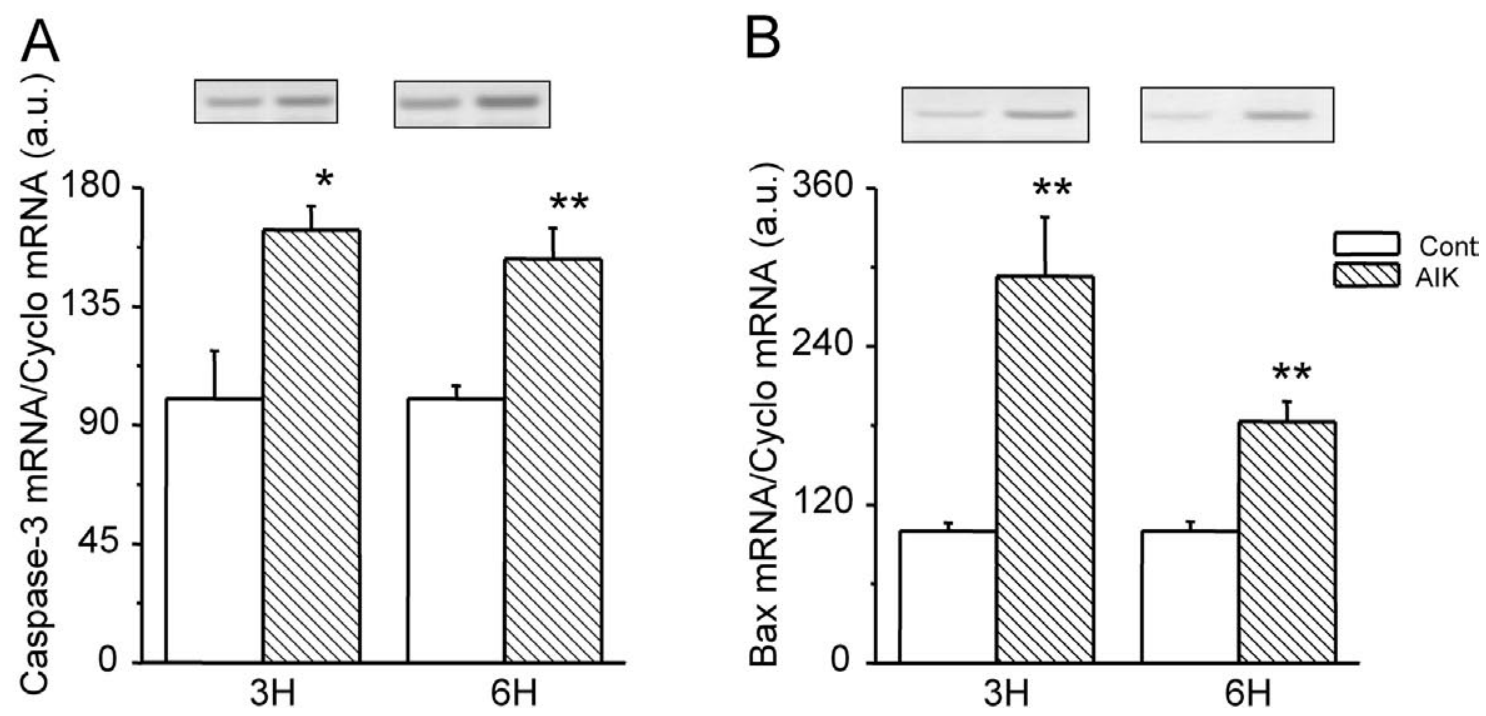

Figure 1. Comparison of mRNA levels of the caspase-3 (A) and Bax (B) in control PC12 cells and PC12 cells after 3 and 6 hours of apoptosis induction by AIK, as described in the text. Cyclophyline (Cyclo) expression was used as a housekeeper gene control for semiquantitative evaluation of PCR. Duration of the treatment by AIK was chosen according to previous experiments (data not shown). Both, 3 and 6 hour treatments resulted in significant increase of caspase- 3 and Bax mRNA levels in comparison with their time-corresponding controls. Each column is displayed as mean \pm S.E.M $(n=5),{ }^{*} p<0.05,{ }^{* *} p<0.01$. Cont, control cells; AIK, cells after apoptosis induction; $3 \mathrm{H}$, apoptosis induction for 3 hours; $6 \mathrm{H}$, apoptosis induction for 6 hours. 
no changes in RyR1 protein amount (Fig. 2B). RyR2 gene expression was also down regulated by induction of apoptosis and mRNA decreased significantly from $100.0 \pm 5.9$ to $63.0 \pm$ $0.5 \%(p<0.01)$ after 3 hours and from $100.0 \pm 10.3$ to $68.0 \pm$ $5.1 \%(p<0.01)$ after 6 hours (Fig. 2C). The amount of RyR2 protein decreased approximately $20 \%$ after 3 hours of apoptosis induction compared to control (Fig. 2D).

There is strong evidence suggesting that enhanced calcium release from internal stores plays an important role in the progression of apoptosis. ER serves as a rapidly exchanging $\mathrm{Ca}^{2+}$ store that contributes to cytosolic calcium cascade by releasing $\mathrm{Ca}^{2+}$ mainly through RyRs and IP3Rs (Verkhratsky and Petersen 2002). Critical role of these receptors in regulation of apoptosis is supported by several studies. Ruiz et al. (2009) showed that blocking of RyRs and IP3Rs attenuated NMDA (N-methyl D-aspartate)-induced ER stress promoting apoptosis in neuronal cells. Guo et al. (2010) showed that si-RyR2 reduces cell death in neonatal cardiomyocytes. Other studies showed that genomic deletion of IP3Rs (Sugawara et al. 1997) or antisense knockdown (Jayaraman and Marks 1997) significantly attenuates apoptosis.

According to results of other authors, after induction of apoptosis, we expected that the gene expression of both RyR1 and RyR2 would increase consequently triggering massive release of $\mathrm{Ca}^{2+}$ from ER leading cells into apoptosis. We observed the gene expression of both RyRs significantly decreased in PC12 cells. Decrease in RyR2 expression was also observed by Salas et al. (2010) during cardiac ischemia. This decrease was similar to that observed at the onset of reperfusion-associated with an increase in the rate of SR $\mathrm{Ca}^{2+}$ release. This paradoxical result was explained by an ischemic damage of RyR2 leading to an increase in the open probability and/or conductance of $\mathrm{Ca}^{2+}$-release channels (Salas et al. 2010).

Zhou et al. (1998) presented that apoptosis can also result from ER stress evoked by inhibition of $\mathrm{Ca}^{2+}$ uptake to ER, by
A
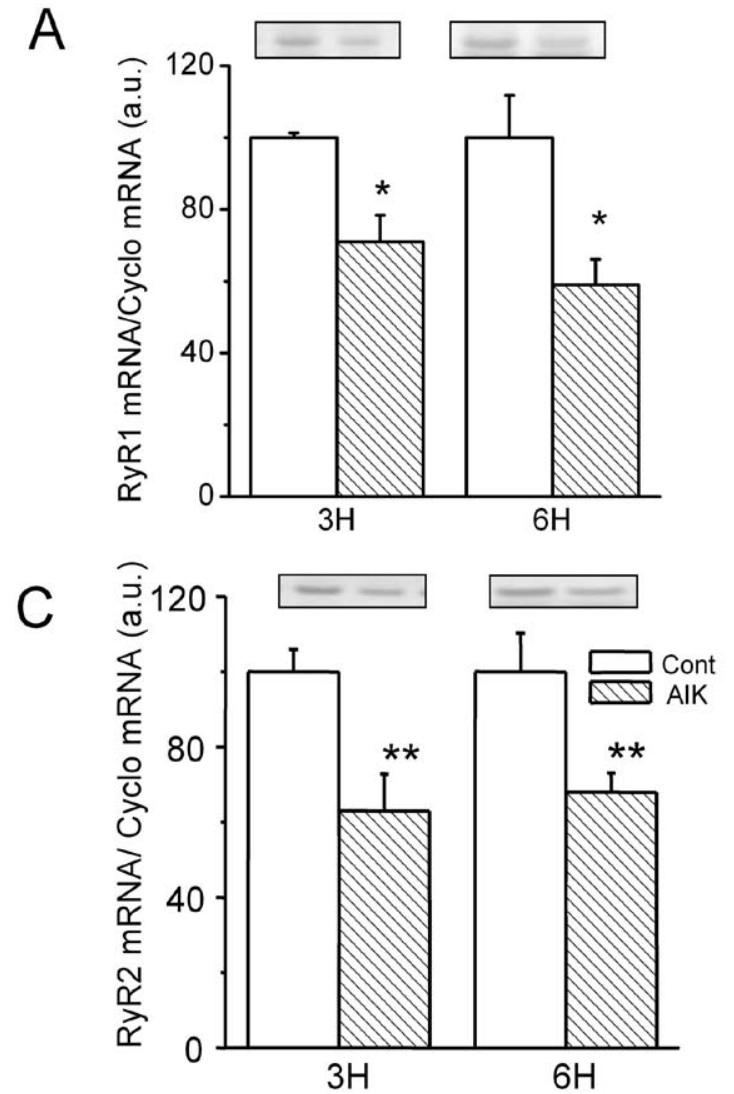

$\mathrm{B}$

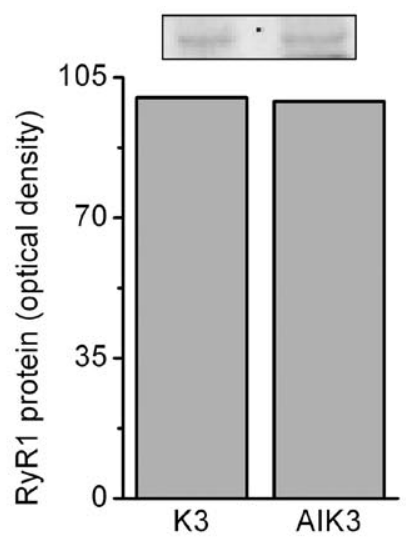

D

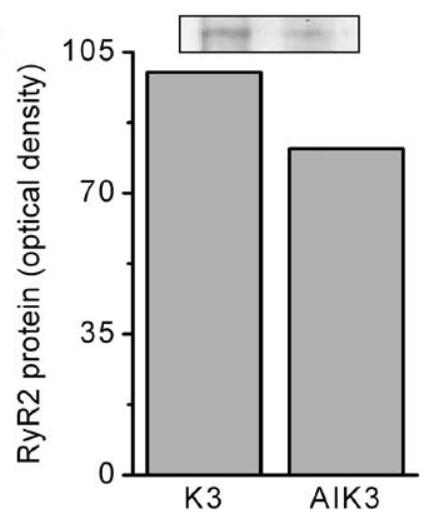

Figure 2. Comparison of the RyR1 mRNA (A) and RyR2 mRNA (C) levels in control PC12 cells and PC12 cells after 3 and 6 hours of apoptosis induction by AIK and typical RyR1 (B) and RyR2 (D) protein levels after 3 hours of apoptosis induction. Both, 3 and 6 hour treatments resulted in significant decrease of RyR1 and RyR2 mRNA levels in comparison with their time-corresponding controls. Cyclophyline (Cyclo) expression was used as a housekeeper gene control for semi-quantitative evaluation of PCR. There was no change observed on protein level of RyR1 compared to corresponding control. RyR2 protein level decreased by $20 \%$ after 3 hours of AIK treatment compared to its time-corresponding control. Each column is displayed as mean \pm S.E.M $(n=5),{ }^{*} p<0.05,{ }^{* *} p<0.01$. Cont, control cells; AIK, cells after apoptosis induction; $3 \mathrm{H}$, apoptosis induction for 3 hours; $6 \mathrm{H}$, apoptosis induction for 6 hours. 
blocking SERCA pump. In our experiments decreased RyR1 and RyR2 expression was accompanied by significantly decreased mRNA levels of SERCA2 (data not shown). Luciani et al. (2009) point that both SERCA and RyR inhibition can activate programmed cell death in $\beta$-cells and that disruption of $\beta$-cell ER $\mathrm{Ca}^{2+}$ handling can trigger multiple apoptosis pathways. Based on these observations it might be possible that induction of apoptosis in PC12 cells inhibited SERCA2 first and observed down regulation of both RyR1 and RyR2 was only following feedback event. More studies need to be performed to elucidate this possibility.

On the other hand there are numerous studies showing the role of $\mathrm{Bcl}-2$ proteins in calcium metabolism (White et al. 2005). Gerasimenko et al. (2010) reported results of their experiments with small molecule inhibitors of $\mathrm{Bcl}-2 /$ Bcl-xL. Their study on pancreatic acinar cells showed that ER contains significant quantities of Bcl-2 family proteins. Molecule inhibitors of $\mathrm{Bcl}-2 / \mathrm{Bcl}-\mathrm{xL}$ caused dissociation of proapoptotic Bax from prosurvival $\mathrm{Bcl}-2$ and $\mathrm{Bcl}-\mathrm{xL}$ and this association was accompanied with the ability of these agents to cause release of $\mathrm{Ca}^{2+}$ from intracellular stores. Interpretation of the findings of Gerasimenko is that dissociating proapoptotic Bcl-2 proteins such as Bax from prosurvival $\mathrm{Bcl}-2$ proteins such as $\mathrm{Bcl}-2$ and $\mathrm{Bcl}-\mathrm{xL}$ increases the sensitivity of IP3Rs and RyRs to activation by calcium as described previously in pancreatic acinar cells (Leite et al. 2002). Works of Chen et al. (2004) and White et al. (2005) demonstrated that $\mathrm{Bcl}-2$ and $\mathrm{Bcl}-\mathrm{xL}$ physically bind to the IP3R and alters its ability to release $\mathrm{Ca}^{2+}$. Addition of Bax prevented this release. Taken together, when associated with proapoptotic proteins, the prosurvival $\mathrm{Bcl}-2$ proteins inhibit the $\mathrm{Ca}^{2+}$ releasing channels, while when dissociated from proapoptotic $\mathrm{Bcl}-2$ proteins, $\mathrm{Bcl}-2$ and $\mathrm{Bcl}-\mathrm{xL}$ increase the sensitivity of the channels to $\mathrm{Ca}^{2+}$ release by increasing their sensitivity for activation by $\mathrm{Ca}^{2+}$ (Gerasimenko et al. 2010).

Also in neuronal cells evidence is accumulating that $\mathrm{Bcl}-2$ constitutes a rheostat for the fine tuning of $\mathrm{Ca}^{2+}$ at the ER by affecting content and release of $\mathrm{Ca}^{2+}$ from ER (Hetz and Glimcher 2008). In cerebral granule cells Lossi et al. (2009) showed that depending on upstream signal, $\mathrm{Ca}^{2+}$ released from the ER signals back and acts as a second messenger that plays a crucial role in the post translation regulation of Bcl-2.

We could possibly speculate that our observation of decreased mRNA and protein expression of RyR1 and RyR2 receptors after induction of apoptosis with strong apoptosis inducer set of chemicals could be explained in concordance with observations of mentioned authors. Decreased expression of RyRs observed in PC12 cells could be also due to Bcl-2 protein increased sensitivity of RyR 1 and RyR2 to $\mathrm{Ca}^{2+}$ resulting in increased ER $\mathrm{Ca}^{2+}$ release. By negative feedback regulation mechanism cell could down-regulate mRNA and protein expression of these receptors.
In conclusion we can state that experimental induction of apoptosis for 3 and 6 hours in PC12 cells diminished the gene expression of main $\mathrm{ER} \mathrm{Ca}^{2+}$ release transporter - RyR. There are many more experiments necessary to be accomplished to explain the mechanism and regulatory pathway. Possible explanation could be searched in modulation effect of apoptotic Bcl-2 family proteins physically and functionally regulating $\mathrm{ER} \mathrm{Ca}^{2+}$ transporters and in transcriptional modulation of $\mathrm{ER} \mathrm{Ca}^{2+}$ transporters according to their modulation function on intracellular $\mathrm{Ca}^{2+}$ concentration triggering apoptotic or necrotic cell death. There is growing evidence that inappropriate transport activity of these ion channels can both negatively and positively modulate ER stress and trigger multiple apoptosis pathways (Luciani et al. 2009).

Acknowledgements. The study was supported by grant APVV 51-0397.

\section{References}

Chen R., Valencia I., Zhong F., McColl K. S., Roderick H. L., Bootman M. D., Berridge M. J., Conway S. J., Holmes A. B., Mignery G. A., Velez P., Distelhorst C. W. (2004): Bcl-2 functionally interacts with inositol 1, 4, 5-trisphosphate receptors to regulate calcium release from the $\mathrm{ER}$ in response to inositol 1,4,5-trisphosphate. J. Cell. Biol. 166, 193-203; doi:10.1083/ jcb.200309146; doi:10.1083/jcb.200309146

Ferreiro E., Oliveira C. R., Pereira C. M. (2008): The release of calcium from the endoplasmic reticulum induced by amyloid-beta and prion peptides activates the mitochondrial apoptotic pathway. Neurobiol. Dis. 30, 331-342; doi:10.1016/j.nbd.2008.02.003; doi:10.1016/ j.nbd.2008.02.003

Gerasimenko J., Ferdek P., Fischer L., Gukovskaya A. S., Pandol S. J. (2010): Inhibitors of Bcl-2 protein family deplete ER $\mathrm{Ca}^{2+}$ stores in pancreatic acinar cells. Pflugers Arch. 460, 891-900; doi: 10.007/s00424-010-0859-4; doi:10.1007/ s00424-010-0859-4

Guo Z., Wang S., Jiao Q., Xu M., Gao F. (2010): RNAi targeting ryanodine receptor 2 protects rat cardiomyocytes from injury caused by simulated ischemia-reperfusion. Biomed. Pharmacother. 64, 184-190; doi:10.1016/j.biopha.2009.09.015; doi:10.1016/j.biopha.2009.09.015

Hajnóczky G., Csordás G., Madesh M., Pacher P. (2000): Control of apoptosis by $\mathrm{IP}(3)$ and ryanodine receptor driven calcium signals. Cell Calcium 28, 349-363; doi:10.1054/ ceca.2000.0169; doi:10.1054/ceca.2000.0169

Hetz C., Glimcher L. (2008): The daily job of night killers: alternative roles of the BCL-2 family in organelle physiology. Trends Cell Biol. 18, 38-44; doi:10.1016/j.tcb.2007.10.003; doi:10.1016/j.tcb.2007.10.003

Hudecova S., Sedlakova B., Kvetnansky R., Ondrias K., Krizanova O. (2010): Modulation of the sodium-calcium exchanger in the rat kidney by different sequential stressors. Stress 13, 15-21; doi:10.3109/10253890902838835 
Jayaraman T., Marks A. R. (1997): T cell deficient in inositol 1.4.5trisphosphate receptor are resistant to apoptosis. Mol. Cell. Biol. 17, 3305-3312

Jurkovicova D., Kopacek J., Stefanik P., Kubovcakova L., Zahradnikova A. Jr., Zahradnikova A., Pastorekova S., Krizanova O. (2007): Hypoxia modulates gene expression of IP3 receptors in rodent cerebellum. Pflugers Arch. 454, 415-425; doi: 10.1007/s00424-007-0214-6; doi:10.1007/ s00424-007-0214-6

Leite M. F., Burgstahler A. D., Nathanson M. H. (2002): Ca2+ waves require sequential activation of inositol trisphosphate receptors and ryanodine receptors in pancreatic acini. Gastroenterology 122, 415-427; doi: 10.1053/ gast.2002.30982; doi:10.1053/gast.2002.30982

Lossi L., Gambino G., Ferrini F., Alasia S., Merighi A. (2009): Posttranslational regulation of BCL2 levels in cerebellar granule cells: A mechanism of neuronal survival. Dev. Neurobiol. 69, 855-870; doi: 10.1002/dneu.20744; doi:10.1002/dneu.20744

Luciani D. S., Gwiazda K. S., Yang T. L., Kalynyak T. B., Bychkivska Y., Frey M. H., Jeffrey K. D., Sampaio A. V., Underhill T. M., Johnson J. D. (2009): Roles of IP3R and RyR Ca ${ }^{2+}$ channels in endoplasmic reticulum stress and beta-cell death. Diabetes 58, 422-432; doi: 10.2337/db07-1762; doi:10.2337/db07-1762

Nathanson M. H., Fallon M. B., Padfield P. J., Maranto A. R. (1994): Localization of the type 3 inositol 1, 4, 5-trisphosphate receptor in the $\mathrm{Ca}^{2+}$ wave trigger zone of pancreatic acinar cells. J. Biol. Chem. 269, 4693-4696

Rizzuto R., Marchi S., Bonora M., Aguiari P., Bononi A., De Stefani D., Giorgi C., Leo S., Rimessi A., Siviero R., Zecchini E., Pinton P. (2009): $\mathrm{Ca}(2+)$ transfer from the ER to mitochondria: when, how and why. Biochim. Biophys. Acta 1787, 1342-1351; doi:10.1016/j.bbabio.2009.03.015; doi:10.1016/j.bbabio.2009.03.015

Rong Y., Distelhorst C. W. (2008): Bcl-2 protein family members: versatile regulators of calcium signaling in cell survival and apoptosis. Annu. Rev. Physiol. 70, 73-91; doi:10.1146/annurev.physiol.70.021507.105852
Ruiz A., Matute C., Alberdi E. (2009): Endoplasmic reticulum $\mathrm{Ca}(2+)$ release through ryanodine and $\mathrm{IP}(3)$ receptors contributes to neuronal excitotoxicity. Cell Calcium 46, 273-281; doi:10.1016/j.ceca.2009.08.005; doi:10.1016/ j.ceca.2009.08.005

Salas M. A., Valverde C. A., Sánchez G., Said M., Rodriguez J. S., Portiansky E. L., Kaetzel M. A., Dedman J. R., Donoso P., Kranias E. G., Mattiazzi A. (2010): The signalling pathway of CaMKII-mediated apoptosis and necrosis in the ischemia/reperfusion injury. J. Mol. Cell Cardiol. 48, 1298-1306; doi:10.1016/j.yjmcc.2009.12.015; doi:10.1016/ j.yjmcc.2009.12.015

Sugawara H., Kurosaki M., Takata M., Kurosaki T. (1997): Genetic evidence for involvement of type 1, type 2 and type 3 inositol 1.4.5-trisphosphate receptors in signal transduction through the B-cell antigen receptor. EMBO J. 16, 3078-3088; doi:10.1093/emboj/16.11.3078

Straub S. V., Giovannucci D. R., Yule D. I. (2000): Calcium wave propagation in pancreatic acinar cells: functional interaction of inositol 1,4,5-trisphosphate receptors, ryanodine receptors, and mitochondria. J. Gen. Physiol. 116, 547-560; doi:10.1085/jgp.116.4.547

Verkhratsky A., Petersen O. H. (2002): The endoplasmic reticulum as an integrating signaling organelle: from neuronal signaling to neuronal death. Eur. J. Pharmacol. 447, 141-154; doi:10.1016/S0014-2999(02)01838-1

Zhou Y. P., Teng D., Dralyuk F., Ostrega D., Roe M. W., Philipson L., Polonsky K. S. (1998): Apoptosis in insulin-secreting cells: evidence for the role of intracellular $\mathrm{Ca}^{2+}$ stores and arachidonic acid metabolism. J. Clin. Invest. 101, 1623-1632; doi:10.1172/JCI1245

White C., Li C., Yang J., Petrenko N. B., Madesh M., Thompson C. B., Foskett J. K. (2005): The endoplasmic reticulum gateway to apoptosis by $\mathrm{Bcl}-\mathrm{X}(\mathrm{L})$ modulation of the InsP3R. Nat. Cell Biol. 7, 1021-1028; doi: 10.1038/ncb1302; doi:10.1038/ncb1302

Received: September 21, 2010

Final version accepted: October 19, 2010 